\title{
Prevalence and Associated Factors of Hepatitis B Surface Antigen (HBsAg) among People Living with HIV (PLWHIV) Attending at CTC Mawenzi Regional Hospital Kilimanjaro, Northern Tanzania
}

\author{
Benedicto Shimula Nyalika \\ Kilimanjaro Christian Medical University College, Kilimanjaro, Tanzania \\ Email: benshimuuu@gmail.com
}

How to cite this paper: Nyalika, B.S. (2021) Prevalence and Associated Factors of Hepatitis B Surface Antigen (HBsAg) among People Living with HIV (PLWHIV) Attending at CTC Mawenzi Regional Hospital Kilimanjaro, Northern Tanzania. Advances in Infectious Diseases, 11, 216-231. https://doi.org/10.4236/aid.2021.112020

Received: March 9, 2021

Accepted: June 13, 2021

Published: June 16, 2021

Copyright $\odot 2021$ by author(s) and Scientific Research Publishing Inc. This work is licensed under the Creative Commons Attribution International License (CC BY 4.0).

http://creativecommons.org/licenses/by/4.0/

\begin{abstract}
Background: Human immunodeficiency virus (HIV) and hepatitis virus (HBV) coinfection are common due to shared modes of transmission between these viruses. Also studies have shown that HIV appears to be a risk factor for reactivation of hepatitis $B$ in patients who have developed hepatitis B surface antibodies HBsAg which is considered as a marker of chronic HBV infection. The magnitude of HIV/HBV coinfection among people living with HIV in Tanzania is not well known. Objective: The aim of this study was to determine the prevalence and associated factors of HBsAg among HIV Positive Clients at CTC at Mawenzi Regional Hospital. Methods: It was a cross sectional study that included 100 HIV Positive CTC clients at Mawenzi Regional Hospital. Ethical clearance was obtained at KCMUCo ethical committee, structured questionnaires with closed-ended question were used to collect the information needed done by interviewing the person, blood sample was collected from median cubital vein and HBsAg Rapid Test Strips were used. Data processing and analysis were done using SPSS version 20. Results: Of 100 HIV patients, only $8(8 \%)$ tested positively for HBsAg. There was a significant association between residence and HBV infection. People from rural areas had high prevalence compared to urban areas (OR 8.71, 95\% CI: 1.029 73.66). Other social demographic and clinical characteristics in this study had no significant association with $\mathrm{HBsAg}$ positivity. Conclusion: Significant numbers of $8 \%$ HIV patients are HBsAg positive. HIV patients from rural residency are more likely to acquire $\mathrm{HBV}$ than Urban residents that showed significant association.
\end{abstract}




\section{Keywords}

HIV, HBV, HBsAg, Care and Treatment Center (CTC)

\section{Introduction}

\subsection{Background}

Hepatitis B is a viral infection that affects the liver and can cause both acute and chronic disease. The virus is transmitted through contact with blood or other fluids of an infected person [1]. Hepatitis B virus is classified as a Hepadinavirus, It is a small $(3.2 \mathrm{~kb})$ partially double-stranded circular Hepadinavirus that consists of the outer surface of envelope composed of HBsAg and surrounds an inner nucleocapsid core that contains $\mathrm{HBcAg}$. $\mathrm{HBcAg}$ can only be found in the liver cells and it marks HBV replication while HBsAg can be found in secretions: saliva, urine, semen, tears, sweat and breast milk, anti-HBs appear after HBsAg disappears several weeks or months. HBsAg is the first marker to appear after infection with HBV, it becomes detectable 2 to 10 weeks after exposure [2].

The Hepatitis B virus can survive outside the body for at least 7 days. During this time, the virus can still cause infection if it enters the body of a person who is not vaccinated, an incubation period of 75 days on average, it ranges $30-180$ days. The virus is detected 30 - 60 days after infection and can persist and develop into chronic Hepatitis B [1].

$\mathrm{HBV}$ is transmitted through contact with HBV-contaminated blood and body fluids. Exposure to HBV transmission has thus been associated with blood transfusions, sharing of needles and syringes by drug users, occupation needle sticks injuries, accidents that involve blood exposures and contact with a broken skin, tattooing and acupuncture. Transmission of HBV may also occur through sexual intercourse or infect from mother to infant most likely during delivery [3].

Several interventions have been introduced to prevent HBV transmission including screening of blood donors and mostly introduction of Hepatitis B virus vaccine which is currently recommended to high risk group such as health care workers.

Worldwide it is estimated that HBV infection affects (5\% to 20\%) of people living with HIV (PLWHIV) (WHO 2016). Coinfection is more common in Asia and Africa with high prevalence of the virus, $25 \%$ of PLWHIV are infected while in less endemic areas, North America, Europe and Australia coinfection are less than $10 \%$ [4].

240 million people worldwide are estimated to be chronically infected with Hepatitis B, cirrhosis and liver cancer among others which are complications of hepatitis that causes death of more than 686,000 people every year [1].

$10 \%$ of 40 million HIV infected individuals have chronic hepatitis B [5]. Epidemiological data from various parts of Africa in rural and urban areas collected 
indicate that rates of hepatitis B coinfection are higher in Sub Saharan Africa than in Western Europe or USA [3].

Both HIV and HBV share common route of transmission. They are both transmitted through sexual and percutaneous route, thus coinfection with both viruses is common. Worldwide it is estimated that $10 \%$ of 40 million HIV infected individuals have chronic hepatitis B [5].

Accumulating evidence suggests that HIV coinfection adversely affects the clinical course of hepatitis. Increased HBV carriage rates, greater levels of HBV viremia, more rapid decline in HBV surface antibody, increased reaction episodes and faster progression to liver cirrhosis are all characteristics of HIV/HBV co infection [6].

Deaths from AIDS related causes have decreased following the introduction and use of Antiretroviral therapy but liver disease has emerged on the leading cause of morbidity and mortality [6]. Tanzania implemented the WHO policy of general HBV vaccination for children as a part of the extended program of immunization. According to notified data a vaccination coverage of $91 \%$ of 1 year -old children was achieved in 2013 [7].

Lamivudine, amtricitabine and tenofovir are nucleoside reverse transcriptase inhibitors included as standard cART regimen in Tanzania and other countries in SSA. Not only they suppress effect against HIV but also these drugs have excellent antiviral activity against HBV. WHO recommends screening of HBV by means of HBsAg testing, so far routine screening for HBsAg is not included in national HIV programs. One reason for this might be there is no enough information about the magnitude of the problem.

\subsection{Literature Review}

The literature search was conducted through; Google scholar, Pub Med, HINARI, and WHO database. Keywords used were HIV and HBV infections, HIV/HBV co-infection also the search based on my research questions. Different studies from America, Asia, Europe and Africa specifically Tanzania conducted between 2005 to 2017 were downloaded.

\subsubsection{Prevalence of HBsAg among PLWHIV}

Worldwide it is estimated that HBV infection affects (5\% to 20\%) of people living with HIV (PLWHIV) (WHO 2016). Coinfection is more common in Asia and Africa with high prevalence of the virus, $25 \%$ of PLWHIV are infected while in less endemic areas North America, Europe and Australia coinfection is less than $10 \%[4]$.

Studies done in Brazil showed the general prevalence of HIV/HBV coinfection to range from $1.6 \%$ to $3.8 \%$ [8] [9] [10]. Moreover, a systematic review and metaphysics study done in Iran in which 49 studies that consisted 170,000 individuals analyzed the overall prevalence in general population was very low and close to $0.00 \%$ [11]. Previous studies show low prevalence as compared to retrospective cohort study in Cambodia between 2003 to 2014, where the esti- 
mated prevalence of HBV co infection was 11.0 [12] which is not far from a study done in china where the overall prevalence was $12.49 \%$ (95\% CI (11.50 13.48), [13].

The Euros IDA study which was prospective observational study, 1802 patients with HIV -1 in 72 countries across Europe were enrolled, 498 patients tested positive for HBsAg (8.7\%). incidence of new AIDS diagnosis was similar in HBsAg positive and HBsAg negative patients. The highest prevalence was found in Argentina 17.8\% then northern and central Europe 9.1\%, southern 8.9\% and Eastern Europe 5.9\% [14].

A cross section study to access Hepatitis B and C confection among patients in tertiary hospitals Nigeria, a total of 200 patients were enrolled in a study. The prevalence of HBsAg was $28.4 \%$ and it was lower in a control subject that had a prevalence of $6.0 \%$ [15]. This prevalence was high as compared to a retrospective study in Senegal between 2006-2010 that included $466 \mathrm{HIV}$ infected patients $58.4 \%$ females, estimated prevalence HBsAg positive patients was 8.8\%, [16]. The variation may be due to different study designs or other unknown factors that need to be investigated.

Also, in Ghana A systematic review metaphysics study of twelve established articles between 1999 to 2016 with overall of 8162 patients reported coinfection prevalence rate ranged from 2.4 - 41.7, the pooled HIV/HBV co infection rate was $13.6 \%$ [17]. A similar study in Senegal with a sample size of 466 had a prevalence of 8.8 [17]. No huge difference from another study in Zimbabwe which was a cross-section, estimated prevalence of $9 \%$ [18].

A study done in Kenya in which 300 HIV patients comprising 129 (43\%) males were enrolled in a study, there were $18(6 \%)$ confections of $\mathrm{HIV} / \mathrm{HBV}$ [19]. The results were the same as a retrospective study between November 2004 to September 2011 done in Tanzania that estimated the prevalence of $6.2 \%$ [20].

The findings from the previous study are not far from another study done in rural Tanzania that was also a retrospective consisted of 272 HIV patients, HBsAg was detected in 25 of 272 (9.2\%, 95\% CI 6.2\% - 13.0\%) the reason may be due to similar study designs used or patients share common exposure variables.

\subsubsection{Associated Factors of HBsAg among PLWHIV}

Association with age and gender:

There was a significant association of HBV coinfection with male gender and age in most of the studies. (OR 2.9, 95\% CI (1.06 - 7.96) P (0.0286)) [8] Also there was a high incidence of infected individuals aged 31 - 50, prevalence was $10.9 \%$ and $7.38 \%$ for males and females respectively $(p=0.245)$ [3] [9]. The HBsAg positivity according to age groups showed that patients between $41-50$ years and those with over 50 years were predominantly $12.2 \%$ and $11.6 \%$ respectively. It was also observed to be lower in patients under 20 years [16]. Among those infected the majority of them aged 25 and 40 years. In relation to gender there was no difference however males had the highest prevalence rate of HBV co infection [19]. 
Other associated factors; the HBV/HIV coinfection has been associated with commercial sex workers, first sexual intercourse and vaccination status [21], also there was an association of patients with poverty in Brazil [10]. Similarly, in sub-Saharan Africa heterosexual exposures are responsible for most of the infections [22]. A study in Tanzania showed that HIV patients co-infected with HBV were more likely to be immunosuppressed at ART initiation [20].

There is no enough published document from Tanzania that shows associated risk factors for HBV infection among HIV patients.

\subsection{Statement Problem}

Since the introduction of highly active antiretroviral therapy (HAART) deaths from AIDS related causes have declined, but liver disease has become the leading cause of morbidity and mortality [6]. Worldwide it is estimated that $10 \%$ of 40 million HIV infected individuals have chronic hepatitis B [5]. Many studies have shown that HIV coinfection adversely affects the clinical course of hepatitis, Increased HBV carriage rates, greater levels of $\mathrm{HBV}$ viremia, more rapid decline in HBV surface antibody, increased reaction episodes and faster progression A to liver cirrhosis are all characteristics of $\mathrm{HIV} / \mathrm{HBV}$ co infection.

The burden of HIV/HBV co-infection is not well known in Tanzania due to limited number of studies available. Therefore, this study is aimed to estimate the prevalence of HBV infection among HIV infected individuals and to investigate factors associated with co-infection at CTC Mawenzi Regional Hospital. The results may help to access the burden of viral Hepatitis in people living with $\mathrm{HIV}$ and to guiding preventive measures to more vulnerable groups.

\subsection{Justification}

HIV coinfection adversely affects the clinical course of Hepatitis B that lead to increase in morbidity and mortality. WHO recommends routine screening of HBV by testing HBsAg among HIV patients but yet it is not practiced one reason may be due to lack of enough information about this problem. Estimating its magnitude and associated factor may help the government (Ministry of Health and Social Warfare) to plan policy on health services regarding this group of people.

\subsection{Study Question}

1) What is the prevalence of HBsAg among PLWHIV attending at CTC Mawenzi Regional Hospital?

2) What are the associated factors of HBV infections among PLWHIV attending at CTC at CTC Mawenzi Regional Hospital?

\section{Objectives}

\subsection{Broad Objective}

To determine prevalence and associated factors of HBsAg among people living 
with HIV at CTC Mawenzi Regional hospital.

\subsection{Specific Objectives}

1). To determine magnitude of HBsAg among people living with HIV.

2). To access factors associated with HBV infection among people living with HIV.

\section{Methodology}

\subsection{Study Design}

It was a hospital based cross-section study that was accessing the prevalence and associated factors of HBsAg among PLWHIV between March to April 2017. The cross section study design was favorable to answer the mentioned research questions since it determines prevailing characteristics in a population at a given point in time and it allows the researcher to look at numerous things at once. It is also less expensive compared to some other study designs.

\subsection{Study Area}

The study was conducted at Mawenzi Regional Hospital that is located in Moshi municipal which is in the Kilimanjaro Region and is situated on the lower slopes of Mount Kilimanjaro. East-west is Arusha-Himo road connecting Arusha and Voi Kenya, just to East of Moshi is the intersection with North-South road eventually connecting with Tanga and Dar es-salaam. All these enhance interactions with different people within and outside the country since most of activities done are trade, tourism and agriculture. Moshi municipal has a population of 184,292 according to census 2012.

Mawenzi Regional Hospital is a public hospital which started in 1956. There are all together 477 workers in hospital, 152 nurses and over 20 doctors. It is a busy hospital which attends over 300 outpatients daily and has 300 beds in its wards. The hospital includes a care and treatment center for people living with HIV.

\subsection{Study Population}

The study included HIV infected patients who attend at CTC clinic Mawenzi regional hospital during their visit in March to April 2017.

\section{Eligibility Criteria}

\section{1) Inclusion criteria}

All HIV infected patients who were attending CTC clinic at Mawenzi Regional Hospital.

\section{2) Exclusion criteria}

- People aged less than 18 years and their parents refused consent.

- People aged $\geq 18$ years who refused to participate.

\subsection{Sample Size Estimation}

The sample size was calculated by using the formula; 


$$
n=\frac{z^{2} p(100-p)}{\varepsilon^{2}}
$$

where

$Z=$ level of confidence ( 1.96 for $95 \%$ confidence level).

$p=$ expected proportion (prevalence of HBV in HIV patients used is $6.2 \%$

(Hawkins et al. 2013) for a study conducted in Dar-es-salaam Tanzania.

$\varepsilon=$ margin of error $=5 \%$.

So the sample size will be 100 patients who will attend at CTC Mawenzi Regional Hospital.

\subsection{Sampling Technique}

Simple random sampling was used to select $100 \mathrm{HIV}$ patients attending at study area during the study period. Patients were given the numbered cards randomly and minimum of 17 patients were selected to participate in each day of the clinic.

\subsection{Variables}

\subsubsection{Dependent Variable}

- HBV infection (HBsAg) among HIV positive patients.

\subsubsection{Independent Variables}

- Social demographic characteristics (age, residency, marital status, educational level, occupation, alcohol intake and history of tattooing).

- Medical history (history of blood transfusion, injections, time since HIV diagnosis, CD4 count (current/enrolled) ARV drugs use, history of HBV vaccination).

- Sexual behavior characteristics (number of partners/condom use).

\subsection{Data Collection Tools}

Questionnaire was used to collect information from the eligible participants, Vacutainer needle and vacutainer tube were used to draw blood for HBsAg testing, centrifuge machine for blood sample separation to get serum and HBsAg Rapid strip (laborex) was used to test for HBsAg.

\subsection{Data Collection Methods and Laboratory Procedures}

\subsubsection{Data Collection Methods}

First I was introduced to the patients who came for CTC clinic by the health personnel in charge. I requested to be given time to introduce myself and the subject of my study to the patients who attend the clinic, the importance of participating in the study and confidentiality were addressed, also they were told on their right agree or refuse to participate in the study. Those eligible were given a concert form to sign.

Face to face interviews was conducted in a separate room. Structured questionnaires with closed-ended questions translated into Kiswahili language were 
used to collect information. After the interviews, HIV patients were prepared for phlebotomy procedures by study personnel. This included blood collection and use of serum to screen hepatitis B by using Antigen Rapid test strip (HBsAg). The data collection was done by the trained study personnel who got the skills in three years of study.

\subsubsection{Laboratory Procedures}

Participants were prepared for sample collection; the median cubital vein was preferred for drawing blood rather than finger prick since the blood needed in higher quantity. The samples were placed for few minutes then centrifuged at $3000 \mathrm{rpm}$ for 3 minutes to get clear serum for serological analysis of HBsAg.

The clear serum obtained was used to screen HBsAg by using rapid test strip. The test had sensitivity and specificity of approximately $99.7 \%$ and $99.3 \%$ respectively when performed according to instruction of the manufacturer (BIOLINE Biotech Ltd, Dart ford UK).

Principle of the test; The HBsAg is a lateral flow chromatographic immunoassay based on the principle of antibody -sandwich technique. The membrane is pre coated with anti-HBsAg antibodies on the test line region of the test. During testing, Hepatitis B surface antigen in the serum or plasma specimen reacts with the particle coated with anti-HBsAg antibody. The mixture migrates upward on the membrane chromatographically by capillary action to react with anti-HBsAg antibodies on the membrane chromatographically by capillary action to react with anti-HBsAg antibodies on the membrane and generate a colored line. The presence of this colored line in the test region indicates a positive result. To serve as procedural control a colored line will always appear in the control lone region indicating that the proper volume of specimen has been added and membrane wicking has occurred.

\subsubsection{Pre-Testing}

Pre-testing of the questionnaires was before the study at KCMC hospital. It involved HIV patients. And pre-testing of the HBsAg strip was done at KCMC clinical laboratory for positive and negative controls.

\subsection{Data Analysis Plan}

Data were cleaned and checked for completeness and consistency before analysis. Analysis was done by using Statistical Package for Social Sciences (SPSS) version 16 software. Descriptive data were summarized using (mean or median with their respective measure of dispersion and proportion). To check the association between $\mathrm{HBV}$ and risk factors, Odds Ratio (OR) with their respective $95 \%$ confidence interval were calculated. P-value of $5 \%$ was taken as significance results.

\subsection{Ethical Consideration}

Ethical approval with No.2046 was obtained from KCMU-College Research Eth- 
ical Committee. The signed letters from the Course Coordinator and the Dean of student of KCMU-College to Mawenzi Regional hospital were used to obtain permission to conduct study. Participants involved in the study were informed about the purpose of the study and asked to sign the consent form prior to the enrollment and were assured on the right to refuse to participate or withdraw from the study. Permission of both patients and Guardians were considered to get assent of people aged less than 18 .

\section{Results}

\subsection{Response Rate}

A total of $100 \mathrm{HIV}$ positive patients were enrolled in the study. Out of 115 participants approached, 102 agreed to participate giving a response rate of $87 \% .2$ participants had incomplete testing for HBsAg hence excluded from the study. Reasons for failure to participate were being busy, need to be paid and some did not understand the importance of this study.

\subsection{Social-Demographic Characteristics of the Participants}

The age of participants ranged from 15 - 69 years with the mean age of 56.45 (SD $11.032)$ years. Age of above 45 (45\%) followed by 35 - 45 (34\%), 25 - 34 (16\%) and $15-24(5 \%)$. Majority were female $67 \%$, participants with primary education were $78 \%$ while only $10 \%$ were employed in government or private sectors while others $44 \%$ and $46 \%$ were not employed and self-employed in agricultural activities, pet trade respectively. Also Majority 51\% were living with their partners, $17 \%$ not married and $32 \%$ either divorced or widowed. The social demographic characteristics are summarized in (Table 1).

\subsection{Clinical Characteristics of Participants}

Of the 100 participants neither had history of HBV vaccination nor self administered intramuscular injections, only one had history of tattooing. $81 \%$ were on ARV use, $80 \%$ were diagnosed of HIV within 10 years. The average enrollment and current CD4 count were 305 cells /micro liter and 433 cells/ micro liter respectively. Clinical characteristics are shortlisted in Table 2.

\subsection{Prevalence of HBV among People Living with HIV}

Among $100 \mathrm{HIV}$ patients screened for HBV only 8 were positive making an overall prevalence of $8 \%$ (Table 3 ).

\subsection{Associated Factors of HBV Infection among HIV Positive Patients}

The association between HBV infection and associated factors is shown in (Table 4). People aged greater than 35 years had high prevalence of HBsAg this may be due to increase of exposure with time though the association was not significant. 
Table 1. Social demographic characteristics of participants $(\mathrm{N}=100)$.

\begin{tabular}{|c|c|c|}
\hline Variable & Frequency & Percentage (\%) \\
\hline \multicolumn{3}{|l|}{ Age } \\
\hline $15-24$ & 5 & 5 \\
\hline $25-34$ & 16 & 16 \\
\hline $35-45$ & 34 & 34 \\
\hline$>45$ & 45 & 45 \\
\hline \multicolumn{3}{|l|}{ Sex } \\
\hline Male & 33 & 33 \\
\hline Female & 67 & 67 \\
\hline \multicolumn{3}{|l|}{ Residence } \\
\hline Rural & 52 & 52 \\
\hline Urban & & 48 \\
\hline \multicolumn{3}{|l|}{ Level of education } \\
\hline No formal education & 6 & 6 \\
\hline Primary education & 78 & 78 \\
\hline Secondary & 16 & 16 \\
\hline \multicolumn{3}{|l|}{ Occupation } \\
\hline Employed & 10 & 10 \\
\hline Self employed & 46 & 46 \\
\hline Not employed & 44 & 44 \\
\hline \multicolumn{3}{|l|}{ Marital status } \\
\hline Single & 17 & 17 \\
\hline Married & 43 & 43 \\
\hline cohabiting & 8 & 8 \\
\hline Separated/divorced & 16 & 16 \\
\hline Widowed & 16 & 16 \\
\hline
\end{tabular}

Table 2. Clinical characteristics of participants $(\mathrm{N}=100)$.

\begin{tabular}{|c|c|c|}
\hline Variable & Frequency & Percentage (\%) \\
\hline \multicolumn{3}{|c|}{ History of tattooing } \\
\hline Yes & 1 & 1 \\
\hline No & 99 & 99 \\
\hline \multicolumn{3}{|c|}{ Blood transfusion } \\
\hline Yes & 9 & 9 \\
\hline No & 91 & 91 \\
\hline \multicolumn{3}{|c|}{ Intramuscular injections } \\
\hline Yes & 0 & 0 \\
\hline No & 100 & 100 \\
\hline \multicolumn{3}{|l|}{ ARV use } \\
\hline Yes & 81 & 81 \\
\hline No & 17 & 17 \\
\hline \multicolumn{3}{|c|}{ Time since HIV diagnosed } \\
\hline$<10 \mathrm{yrs}$ & 80 & 80 \\
\hline$>10 \mathrm{yrs}$ & 20 & 20 \\
\hline \multicolumn{3}{|c|}{ Enrollement CD4 count (cells/ul } \\
\hline$<200$ & 34 & 40 \\
\hline $200-350$ & 13 & 15.3 \\
\hline$>350$ & 38 & 44.7 \\
\hline \multicolumn{3}{|c|}{ Current CD4 count (cells/ul } \\
\hline$<200$ & 13 & 19.4 \\
\hline $200-350$ & 7 & 10.4 \\
\hline$>350$ & 47 & 70.1 \\
\hline
\end{tabular}


Table 3. Prevalence of HBsAg among HIV positive patients $(\mathrm{N}=100)$.

\begin{tabular}{ccc}
\hline HBsAg status & $\mathbf{n}$ & $\%$ \\
\hline Positive & 8 & 8 \\
Negative & 92 & 92 \\
\hline
\end{tabular}

Table 4. Associated factors of HBsAg infection among HIV positive attending at CTC Mawenzi Regional Hospital $(\mathrm{N}=100)$.

\begin{tabular}{|c|c|c|c|c|}
\hline Variables & Total n (\%) & $\begin{array}{c}\text { HBsAg } \\
\text { positive (\%) }\end{array}$ & OR (95\% CI) & $\mathrm{P}$-value \\
\hline \multicolumn{5}{|l|}{ Sex } \\
\hline Male & $33(33)$ & $2(6.1)$ & \multirow{2}{*}{$0.656(0.125-3.442)$} & \multirow{2}{*}{0.656} \\
\hline Female & $67(67)$ & $6(9.1)$ & & \\
\hline \multicolumn{5}{|l|}{ Age } \\
\hline $15-24$ & $5(5)$ & 0 & \multirow{4}{*}{$0.593(0.22-1.62)$} & \multirow{4}{*}{0.308} \\
\hline $25-34$ & $16(16)$ & 0 & & \\
\hline $35-45$ & $34(34)$ & $4(11.8)$ & & \\
\hline$>45$ & $45(45)$ & $4(8.9)$ & & \\
\hline \multicolumn{5}{|l|}{ Residence } \\
\hline Rural & $48(48)$ & $7(87.5)$ & \multirow{2}{*}{$8.707(1.03-73.66)$} & \multirow{2}{*}{0.047} \\
\hline Urban & $52(52)$ & $1(12.5)$ & & \\
\hline \multicolumn{5}{|l|}{ Marital status } \\
\hline Single & $17(17)$ & $1(12.5)$ & \multirow{5}{*}{$\begin{array}{c}0.725 \\
(0.393-1.338)\end{array}$} & \multirow{5}{*}{0.303} \\
\hline Married & $43(43)$ & $3(37.5)$ & & \\
\hline cohabiting & $8(8)$ & $0(0.0)$ & & \\
\hline Separated & $16(16)$ & $2(25.0)$ & & \\
\hline Widowed & $16(16)$ & $2(25.0)$ & & \\
\hline \multicolumn{5}{|l|}{ Education } \\
\hline No formal & $6(6)$ & $2(25.0)$ & $0.133(0.009-1.87)$ & 0.135 \\
\hline Primary & $78(78)$ & $5(62.5)$ & \multirow[t]{2}{*}{$0.973(0.106-8.942)$} & \multirow[t]{2}{*}{0.981} \\
\hline Secondary & $16(16)$ & $1(12.5)$ & & \\
\hline \multicolumn{5}{|l|}{ Occupation } \\
\hline Employed & $10(10)$ & $1(12.5)$ & \multirow{3}{*}{$\begin{array}{l}0.659(0.061-7.0830 \\
0.768(0.162-3.647)\end{array}$} & \multirow{3}{*}{$\begin{array}{l}0.73 \\
0.74\end{array}$} \\
\hline Self employed & $46(46)$ & $4(50)$ & & \\
\hline Not employed & $44(44)$ & $3(37.5)$ & & \\
\hline \multicolumn{5}{|l|}{ Alcohol intake } \\
\hline Yes & $28(28)$ & $3(37.5)$ & \multirow{2}{*}{$1.608(0.358-7.230)$} & \multirow{2}{*}{0.536} \\
\hline No & $72(72)$ & $5(62.5)$ & & \\
\hline \multicolumn{5}{|c|}{ History of tattooing } \\
\hline Yes & $1(1)$ & $0(0.0)$ & \multirow{2}{*}{-} & \multirow{2}{*}{-} \\
\hline No & 99 (99) & $8(8.1)$ & & \\
\hline \multicolumn{5}{|c|}{ History of blood transfusion } \\
\hline Yes & $9(9)$ & $0(0.0)$ & & \\
\hline No & $91(91)$ & $8(100)$ & - & - \\
\hline Ear pricing & & & & \\
\hline Yes & $64(64)$ & $5(62.5)$ & & \\
\hline No & $36(36)$ & $3(37.5)$ & $0.932(0.209-4.150)$ & 0.932 \\
\hline HBV vaccinatio & & & & \\
\hline Yes & $0(0.0)$ & $0(0.0)$ & & - \\
\hline No & 100 & $8(100)$ & - & - \\
\hline Condom use & & & & \\
\hline Yes & $43(43.9)$ & $2(25.0)$ & $0.398(0.076-2.081)$ & 0.275 \\
\hline No & $55(56.1)$ & $6(75.0)$ & & \\
\hline
\end{tabular}




\section{Continued}

\begin{tabular}{ccccc}
\hline sexual partners & & & & \\
1 & $45(59.2)$ & $3(60)$ & $1.036(0.163-6.592)$ & 0.36 \\
$>1$ & $31(40.8)$ & $2(40)$ & & \\
Time since HIV diagnosed & & & & \\
$<10$ yrs & $80(80)$ & $8(100)$ & & \\
$>10$ yrs & $20(20)$ & $0(0)$ & & \\
ARV use & & & & \\
Yes & $81(82.7)$ & $5(71.4)$ & $0.592(0.109-3.22)$ & 0.54 \\
No & $17(17.3)$ & $2(28.6)$ & & 0.98 \\
Enrollment CD4 count (cells/ $\mu \mathrm{l})$ & & & & \\
$<200$ & $34(40)$ & $3(42.9)$ & & \\
$200-300$ & $13(15.3)$ & $1(14.3)$ & $0.88(0.16,4.7)$ & 0.98 \\
$>300$ & $38(44.7)$ & $3(42.9)$ & $1.03(0.09,10.8)$ & \\
Current CD4 count (cells $/ \mu \mathrm{l})$ & & & & \\
$<200$ & $13(19.4)$ & 0 & & \\
$200-300$ & $7(10.4)$ & $1(16.7)$ & $0.85(0.86-8.44)$ & 0.89 \\
$>300$ & $47(70.1)$ & $5(83.3)$ & & \\
\end{tabular}

There was a significant association between residence and HBV infection people from rural areas had high prevalence compared to urban areas (OR 8.71, 95\% CI: 1.029 - 73.66). Other social demographic and clinical characteristics like age, sex, marital status, alcohol intake, number of sexual partners, education, CD4 count had no significant association with HBsAg positivity.

\section{Discussion}

\subsection{General Discussion}

This study examined the prevalence and associated factors of HBsAg among HIV positive patients. The prevalence was found to be $8 \%$. There was a significant association of place of residency and HBV infection among HIV patients where it was observed that participants from rural areas had 8.7 higher odds of HBV infection compared to those from urban areas.

The prevalence estimated in this study is high compared to the one study done in northern rular Tanzania in Arusha [23]. Reason explained for this low prevalence was that majority of participants were Maasai inhabitants, difference in customary habits, historical isolation and or lack of access to health care contrary to participants of this study who are chagga tribe, exposed to interaction with other people from different places and had access to health care services. Another study in Tanzania at St Francis Referral Hospital in Ifakara Morogoro reported the prevalence comparable to figures obtained in this study. This suggests that the prevalence estimated from this study is acceptable since the participant seems to have same characteristics and slightly different geographical locations. Similar methodology was used in screening HBsAg.

Prevalence obtained in this study seems to be slightly high as compared to a retrospective study done in Dar es salaam Tanzania which found the prevalence not far from retrospective study in Kenya [19] [20]. The reason may be due to 
small sample size used in this study or the prevalence has kept on rising in the last four years since no any intervention is done.

Contrary to the findings of this study, high prevalence was reported in Nigeria and there was an association with polygamous nature of men around the region [15]. This factor was not observed in this study in which majority responded to have only one partner. Other latest cross-section facility based study in Ethiopia reported a similar prevalence as obtained in this study that gave robustness of the findings.

This study has shown very high prevalence compared to reported studies in Brazil [8] [9] [10]. Considering this low prevalence, the coverage of Hepatitis B vaccination in Brazil was over $92 \%$ which is preventive against $\mathrm{HBV}$ infections. With gender, the prevalence was high in males compared to females. This is contrary from many other studies that show high prevalence in males compared to females [16] [24]. The difference of the findings may be due to small sample size used.

The study found a significant association between HIV/HBV coinfection and residence. People living with HIV from rural areas had 8.7 higher odds of contracting HBV infection compared to those living in urban areas. The reasons may be HIV patients in urban attend other CTC located in Moshi Urban or they attend to other places due to fear of stigmatization. However, studies should be done even to access knowledge of HBV transmission due to this high prevalence.

Despite the importance of vaccination to prevent HBV infection, its coverage is very low. A study done at Muhimbili National Hospital between July to September 2015 examining Hepatitis B vaccination coverage among health care worker reviled only 198 (56.9\%) of 348 health care workers interviewed had received vaccination [25]. This coverage is very low if generalized to the total population as healthcare workers have high awareness of the importance of vaccination and are in a risk of contracting HBV infection.

\subsection{Conclusion}

Data provide hospital based determination of the prevalence of HBV and associated factor among HIV positive individuals at CTC Mawenzi that may be generalized to the population of people living with HIV. Therefore, it is possible to conclude that significant number of $8 \%$ HIV positive individuals are co-infected with HBV. HIV patients from rural residency were more likely to acquire HBV than Urban residents that showed a significant association.

\subsection{Recommendation}

There was an association between HBsAg and residence, this can be further investigated to establish a cause.

Health care workers in CTC should be trained to access risk factors and screen for HBsAg so as to offer a preventive education.

There should be a national policy that guides all people to be vaccinated 
against Hepatitis B virus infection, priority should be provided especially to people exposed to the risk factors.

\subsection{Study Limitation and Strength}

This was a cross-sectional study unable to adequately establish a causal relationship between time of exposure and subsequent infection, however, the results can be implied to approximate and prepare for clinical care for HIV positive individuals.

Time limit of data collection and there were no funds provided to conduct this study. Also Ethical approval was obtained very late prior to data collection.

The study might have failed to show association between HBsAg and several associated factors due to small sample size.

\section{Conflicts of Interest}

The author declares no conflicts of interest regarding the publication of this paper.

\section{References}

[1] World Health Organization (2016) Hepatitis B.

[2] Brooks, G.F., Carroll, K.C., Butel, J.S., Morse, S.A. and Mietzner, T.A. (2013) Jawetz, Melnick \& Adelberg's Medical Microbiology. 26th Edition, Mc GrawHill, New York

[3] Franzeck, F.C., Ngwale, R., Msongole, B., Hamis, M., Abdul, O., Henning, L., Letang, E., Mwaigomole, G., Battegay, M., Hatz, C. and Tanner, M. (2013) Viral Hepatitis and Rapid Diagnostic Test Based Screening for HBsAg in HIV-Infected Patients in Rural Tanzania. PLoS ONE, 8, e58468. https://doi.org/10.1371/journal.pone.0058468

[4] Engla, N.E.W. (2010) New England Journal Perspective, 363.

[5] Thio, L.C. (2009) Hepatitis B and Human Immunodeficiency Virus Coinfection. Hepatology, 49, S138-S145. https://doi.org/10.1002/hep.22883

[6] Tsuchiya, N., Pathipvanich, P., Rojanawiwat, A., Wichukchinda, N., Koga, I., Koga, M., Auwanit, W., Kilgore, P.E., Ariyoshi, K. and Sawanpanyalert, P. (2013) Chronic Hepatitis B and C Co-Infection Increased All-Cause Mortality in HAART-Naive HIV Patients in Northern Thailand. Epidemiology \& Infection, 141, 1840-1848. https://doi.org/10.1017/S0950268812002397

[7] Mueller, A., Stoetter, L., Kalluvya, S., Stich, A., Majinge, C., Weissbrich, B. and Kasang, C. (2015) Prevalence of Hepatitis B Virus Infection among Health Care Workers in a Tertiary Hospital in Tanzania. BMC Infectious Diseases, 15, Article No. 386. https://doi.org/10.1186/s12879-015-1129-Z

[8] Zago, A.M., Machado, T.F., Cazimir, F.L. and Miranda, A.E. (2007) Prevalence and Risk Factors for Chronic Hepatitis B in HIV Patients Attended at a Sexually-Trasmitted Diseases Clinic in Vitoria. Brazilian Journal of Infectious Disease, 11, 475-478. https://doi.org/10.1590/S1413-86702007000500007

[9] Filho, P., Martins, A., Tannouri, T.N., Troiani, C., Ascêncio, E.L., Bonfim, R., et al. (2009) Seroplevalence of HBV, HCV, and HIV Co-Infecton in Selected Induviduals from State of Sao Paulo, Brazil. Memorias do Instituto Oswaldo Cruz, 104, 960-963. 
https://doi.org/10.1590/S0074-02762009000700003

[10] Brasileira, S., Tropical, D.M., Martins, S., Livramento, A. and Andrigueti, M. (2014) The Prevalence of Hepatitis B Virus Infection Markers and Socio-Demographic Risk Factors in HIV-Infected Patients in Southern Brazil. Revista de Sociedade Brasileira de Medicina Tropical, 47, 552-558.

https://doi.org/10.1590/0037-8682-0109-2014

[11] Almasi-Hashian, A., Ayubi, E., Mansori, K., Salehi-vaziri, M., Moradi, Y., Gholamaliei, B., et al. (2018) Prevalence of Hepatitis B Virus Infection among Iranian High Risk Groups: A Systematic Review and Meta-Analysis. Gastroenterology and Hepatology from Bed to Bench, 11, 91-100.

[12] Van Griensven, J., Phirum, L., Choun, K., Thai, S., De Weggheleire, A. and Lynen, L. (2014) Hepatitis B and C Co-Infection among HIV-Infected Adults While on Antiretroviral Treatment: Long-Term Survival, CD4 Cell Count Recovery and Antiretroviral Toxicity in Cambodia. PLoS ONE, 9, e88552.

https://doi.org/10.1371/journal.pone.0088552

[13] Zhou, Y.-H., Yao, Z.-H., Liu, F.-L., Li, H., Jiang, L., Zhu, J.-W. and Zheng, Y.-T. (2012) High Prevalence of HIV, HCV, HBV and Co-Infection and Associated Risk Factors among Injecting Drug Users in Yunnan Province, China. PLoS ONE, 7, e42937. https://doi.org/10.1371/journal.pone.0042937

[14] Konopnicki, D., Mocroft, A., de Wit, S., Antunes, F., Ledergerber, B., Katlama, C., Zilmer, K., Vella, S., Kirk, O. and Lundgren, J.D. (2005) Hepatitis B and HIV: Prevalence, AIDS Progression, Response to Highly Active Antiretroviral Therapy and Increased Mortality in the EuroSIDA Cohort. AIDS, 19, 593-601. https://doi.org/10.1097/01.aids.0000163936.99401.fe

[15] Balogun, T., Emmanuel, S. and Ojerinde, E. (2013) HIV, Hepatitis B and C Viruses' Coinfection among Patients in a Nigerian Tertiary Hospital. Pan African Medical Journal, 12, Article No. 100.

[16] Lô, G., Sow-Sall, A., Diop-Ndiaye, H., Mandiouba, N.C.I.D., Thiam, M., Diop, F., et al. (2015) Prevalence of Hepatitis B Markers in Senegalese HIV-1 Infected Patients. Journal of Medical Virology, 88, 461-465. https://doi.org/10.1002/jmv.24344

[17] Agyeman, A.A. and Asenso, O.R. (2016) Prevalence of HIV and Hepatitis B Coinfection in Ghana: A Systematic Review and Metaphysics. AIDS Research and Therapy, 13, Article No. 23. https://doi.org/10.1186/s12981-016-0107-x

[18] Baudi, I., Lijima, S., Chin'ombe, N., Mtapuri-Zinyowela, S., et al. (2016) Molecular Epidemiology of Co-Infection with Hepatits B and Human Immmunodeficiency Virus (HIV) among Adult Patients in Harare, Zimbabwe. Journal of Medical Virology, 89, 257-266. https://doi.org/10.1002/jmv.24641

[19] Muriuki, B.M., Gicheru, M.M., Wachira, D. and Nyamache, A.K. (2013) Prevalence of Hepatitis B and C Viral Co-Infections among HIV-1 Infected Individuals in Nairobi, Kenya. BMC Research Notes, 6, Article No. 363.

https://doi.org/10.1186/1756-0500-6-363

[20] Hawkins, C., Christian, B., Ye, J., Nagu, T., Aris, E., Chalamilla, G., Spiegelman, D., Mugusi, F., Mehta, S. and Fawzi, W. (2013) Prevalence of Hepatitis B Co-Infection and Response to Antiretroviral Therapy among HIV-Infected Patients in Tanzania. AIDS, 27, 919-927. https://doi.org/10.1097/QAD.0b013e32835cb9c8

[21] Apidechkul, T. and Pongwiriyakul, S. (2016) Factors Associated with HIV and HBV Co-Infection in Northern Thailand. Asian Pacific Journal of Tropical Disease, 6, 174-178. https://doi.org/10.1016/S2222-1808(15)61008-8

[22] Alter, M.J. (2006) Epidemiology of Viral Hepatitis and HIV Co-Infection. Journal of 
Hepatology, 44, S6-S9. https://doi.org/10.1016/j.jhep.2005.11.004

[23] Debes, J.D., Stauffer, W.M., Jacobson, M. and Boulware, D. (2015) Low Rates of Hepatitis B and Human Immunodeficiency Virus Coinfection in Rural Northern Tanzania. Journal of Global Infectious Diseases, 7, 47-48.

https://doi.org/10.4103/0974-777X.150893

[24] Nwolisa, E., et al. (2013) Prevalence of Hepatitis B Co-Infection amongst HIV Infected Children Attending Care and Treatment Centre in Owerri, South-Eastern Nigeria. Pan African Medical Journal, 14, Article No. 89.

https://doi.org/10.11604/pamj.2013.14.89.1711

[25] Aaron, D., Nagu, T.J., Rwegasha, J. and Komba, E. (2017) Hepatitis B Vaccination Coverage among Healthcare Workers at National Hospital in Tanzania: How Much, Who and Why? BMC Infectious Diseases, 17, Article No. 786.

https://doi.org/10.1186/s12879-017-2893-8 